\title{
Miniature design of T-Shaped frequency Reconfigurable antenna for S-Band Application using Switching Technique
}

\author{
Omar El Maleky ${ }^{1}$, Farid Ben Abdelouahab ${ }^{2}$, Mohammad Essaaidi ${ }^{3}$, Nasri Abdelfatah ${ }^{4}$ \\ ${ }^{1,2}$ Faculty of Sciences, Abdelmalek Essaadi University, Tetuan, Morocco \\ ${ }^{3}$ National School of Informatics and Systems Analysis, Mohamed V University, Rabat Morocco \\ ${ }^{4}$ Faculty of Sciences and Technology, Bechar University, Bechar, Algeria
}

\begin{tabular}{|c|c|}
\hline Article Info & ABSTRACT \\
\hline $\begin{array}{l}\text { Article history: } \\
\text { Received Jan 12, } 2017 \\
\text { Revised Jun 7, 2017 } \\
\text { Accepted Aug 11, } 2017\end{array}$ & $\begin{array}{l}\text { The article presents a miniature antenna with a simple geometry and a simple } \\
\text { approach for reconfiguration. In order to make the T-shaped antenna } \\
\text { frequency reconfigurable, we integrated Switches in specific positions. The } \\
\text { location of the switches is determined following a study of the distribution of } \\
\text { the surface currents of the suggested antenna. Indeed, we found that the } \\
\text { insertion of switches in places where the concentrations of surface currents }\end{array}$ \\
\hline $\begin{array}{l}\text { Keywords: } \\
\text { Compact antenna } \\
\text { MEMS } \\
\text { PIN diode } \\
\text { RF switch } \\
\text { Switching technique } \\
\text { Tunable antenna }\end{array}$ & $\begin{array}{l}\text { are high is irrelevant. In fact, to redirect current flow, the PIN diodes or RF } \\
\text { Switch must be placed in positions where the distribution of the surface } \\
\text { currents is of low concentration. These locations facilitate the establishment } \\
\text { of new trajectories of the flux of current. As a result, a miniature tunable } \\
\text { antenna dimension } 20 \mathrm{~mm} * 20 \mathrm{~mm} * 1.6 \mathrm{~mm} \text { printed on FR4 substrate with } 4.4 \\
\text { permittivity and with } 0.04 \text { loss tangent, the antenna can be adopted in } \\
\text { many communication devices in view of its small size, its low manufacturing } \\
\text { cost and performance on frequency sweep, the antenna operates in S-Band } \\
\text { with an acceptable band and gain. The antenna is simulated and optimized } \\
\text { using CST Microwave Studio. }\end{array}$ \\
\hline
\end{tabular}

Copyright (c) 2017 Institute of Advanced Engineering and Science.

Corresponding Author:

All rights reserved.

Omar El Maleky,

Department of physics, laboratory materials and radiation,

Faculty of Sciences,

Abdelmalek Essaadi University, Tetuan, Morocco,

Email: o.elmaleky@gmail.com

\section{INTRODUCTION}

Nowadays, with the emergence of new standards, new telecommunication systems must be able to include a large number of functionalities to meet the requirements to coexist several standards on the same antenna, to reduce interference with other standards' Users, to improve the transmission rate of the transmissions, to avoid the fading phenomena, to ensure a better efficiency in the reception of the signal. Because of this, the deployed antennas must be able to adapt to such an evaluative and variable environment [1-2]. The agile antennas (in frequency, in radiation patterns, and in polarization) then appear as potential candidates to meet the requirements imposed with a minimum of size and complexity. The development of active components such as PIN diodes, varicaps diodes, and MEMS, used to produce agility and accelerate the rapid evolution of these antennas. Nevertheless, the polarization circuits of these components still pose a major problem in making the antennas agile. The concept of reconfigurable antennas (or agile antennas) is not new. For many years, this type of antenna has been the subject of an important research [1-2]. The first developments dated back to the end of the 1960s by D.Schaubert's patent Frequency-Agile, Polarization Diverse Microstrip Antenna, and Frequency Scanned Arrays in 1983[3]. However, the development of antenna diversity techniques has attracted considerable and growing interest for smart antennas and contributed greatly to the design of new reconfigurable antenna devices in order to cope with the increasing number of users, the requested functionalities, and the transmission rate. Designed antennas should be able to modify their operating frequencies, bandwidths, polarizations and radiation patterns independently in order to adapt to their changing environment; their context of use and their performance optimization. 
The development of these antennas presents us with very important challenges. These challenges lie not only in obtaining desired levels of antenna functionality but also in integrating these functionalities into complete systems to achieve an efficient and low-cost solution. The polarization circuits of the active elements can also constitute a strong constraint by their consumption and the losses they introduce. There are also issues relative not only to the non-linearity of the components but also to the cost of these components.

The reconfiguration techniques used in the literature mainly use the following active components: MEMS [4], PIN diodes or RF devices [6-8], Varicap [9], optical reconfiguration techniques [10-11] ; we can also find reconfigurable antenna based on mechanical techniques [12] and still others a mixture of several techniques [13-15]. In this work we set out a miniature antenna with a simple reconfiguration technique to cover the S-band with flexibility and give important frequency responses to the targeted band. The prototype simulated by CST [16], a high level of similarity between the numerical and experimental data.

\section{GEOMETRY OF ANTENNA WITHOUT RECONFIGURATION}

The figure 1 describes the dimensions of our specimens; it's a printed antenna on a substrate FR4 dimension $(20 * 20 * 1.6) \mathrm{mm}$, the antenna is of T-shape, is presented in three different lengths form of copper $(8 * 2 \mathrm{~mm}, 16 * 2 \mathrm{~mm}$ and $18 * 2 \mathrm{~mm})$ and separated by a distance of $1.5 \mathrm{~mm}$. A partial ground dimension of $20 \mathrm{~mm} * 4 \mathrm{~mm}$, the antenna fed by a $50 \Omega$ coaxial port.

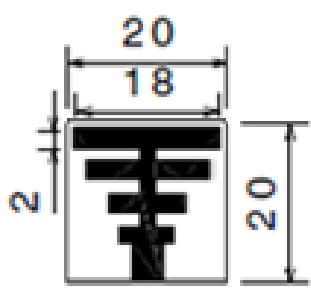

(a)

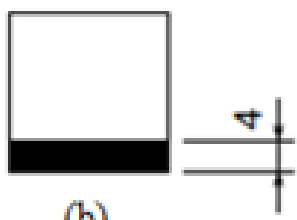

(b)

Figure 1. The dimensions of the antenna

\section{CHOICE OF THE RECONFIGURABLE}

In this part of the article, we review the various electronic techniques that can be used to achieve a reconfiguration in frequency of our antenna; we choose to discuss MEMS technology (a definition, Principle of operation and its categories) also Varactor diode, PIN diode and the FET transistor used a lot in the microelectronics. And we end this part with our approach, which we adopt to maintain the reconfiguration in frequency for the structure introduced.

\subsection{Reconfiguration by MEMS technologies}

Most of these microswitches have a parallel type capacitive architecture that finds its application in coplanar configurations. This has the advantage of being compatible with MMIC circuits, flip-chip technology and low loss technologies [17]. The first achievements were made by Goldsmith et al. [18-20] in 1995. Over the past decade, RF MEMS switches have been used in telecommunications because of many advantages. Apart from other options such as small size, good linearity and good insulation, MEMS switches are considerable devices that use a mechanical movement to obtain a short circuit or an open circuit in the RF transmission line. The forces required for mechanical movement can be obtained using models, electrostatic or magneto-static heat. The operation of the MEM switches is relatively simple. There is a cantilevered beam connected to the source and floats above the grid and drain. When a bias voltage (source-carrier voltage of +/- 90VDC) is applied to the grid, the voltage difference creates an attraction that pulls the cantilever beam towards the drain causing a source to drain; figure 2 presents the example of commercial MEMS RMSW201.

MEMS have the following technical advantages: low power consumption, low insertion loss and high isolation (like mechanical switches) but are small in size, light weight and low cost (like semiconductor switches). On the other hand, they generate the following drawbacks; they may need expensive packaging to protect the movable MEMS bridges against the environment, high losses at microwave also in mm-wave frequencies and limited power-handling capability [21-22]. 


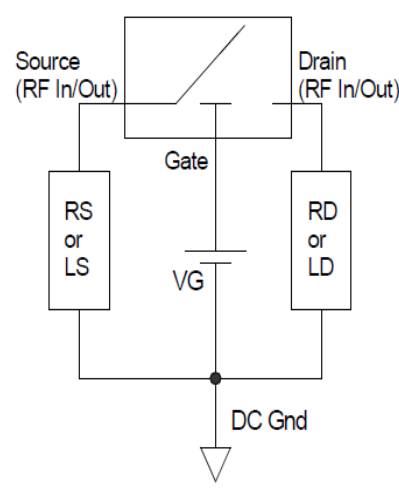

Figure 2. Equivalent circuit model of commercial MEMS RMSW201

\subsection{Reconfiguration by using Varicap diode}

Varactors diodes (variable-capacitance diodes) are components whose junction capacitance varies in compliance with the applied voltage. They have relatively high capacitance values with a low polarization value $(0.5 \mathrm{~V})$. Their low leakage current ensures good electrical performance. Among the many agile circuits incorporating varactor diodes, it is possible to show the example of a microstrip antenna array (patch), in which each antenna is represented by a RLC resonator whose R, L and C are fixed (figure 3). Thus, to shift the network operating frequency, it is enough to insert one or more varactor diodes between the radiating elements (RLC circuit) and their ground plane [23-24].

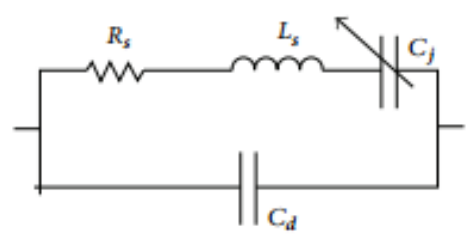

Figure 3. Equivalent circuit model of varactor diode

The main disadvantage associated with the use of varactor diodes, in addition to the permissible power limitation of the circuits, lies in the large losses generated by the high value of the diode series Rs resistance, which greatly reduces the quality factor of the circuits. The use of negative resistance in the circuit can nevertheless limit the losses generated by this resistor [24-26], to the detriment of the noise factor and the linearity

\subsection{Reconfiguration by using PIN diode or FET transistor}

The PIN and FET switches have a high switching speed, low weight and space. However, insertion losses and actuating voltages limit their integration potential in agile circuits.

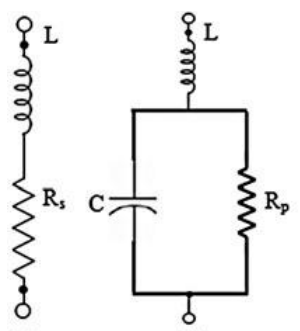

(a) (b)

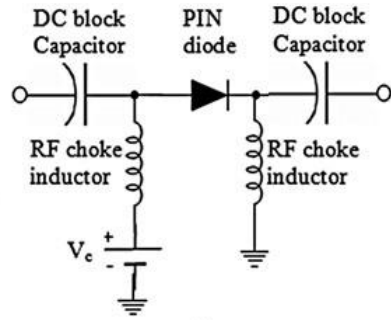

(c)

Figure 4. Equivalent circuit and configuration of PIN diode bias circuit. (a) Forward bias, (b) reverse bias, and (c) bias circuit. 
Figure 4 shows a PIN diode used as a switch in the same RF signal direction. It can be implanted on micro ribbon. By applying a positive voltage, the diode behaves as low impedance and the RF signal is on. On the other hand, when the voltage is inverted (negative), the diode behaves like very high impedance, and in this case the RF signal is totally reflected at the input.

A FET transistor can be used not only as a controlled switch or for amplification, but also as a voltage stabilizer. This transistor, which is made of three active electrodes, enables a current or voltage to be monitored by one input electrode (grid) on one of the output electrodes.

This type of semiconductor component can be integrated on monolithic MMIC circuits and their small space allows the production of switching matrices that can be used in a wide range of applications. On the other hand, for frequencies above $1 \mathrm{GHz}$, these switches show large insertion losses when activated (1-2 $\mathrm{GHz})$, and low isolation when the switches are blocked (-20 dB) [26-27].

\section{PROPOSED COMMUTATION TECHNIQUE}

As mentioned in the abstract, the study of current distribution shows that we can control the path of this current; so the location of switches in optimal position redirect current path. When we simulate the surface current density we find out that the insertion of switches in places where the concentrations of surface currents are high is irrelevant. In fact, to redirect current flow, the electronic component switch must be placed in positions where the distribution of the surface currents is of low concentration. These locations ease the establishment of new trajectory then a different radiation and, therefore, new frequency responses.

The idea is to simulate the connection or disconnection which shows the presence or absence of the electric current exactly as the passing or blocking mode of a PIN diode does by a simple microstrip line in the optimal position.

We have placed six RF switches to give six additional frequencies (figure 5). A major technological problem has arisen at this stage concerning the polarization circuit of diodes in view of the size of the proposed antenna. The design of such a circuit is complicated, which makes its implementation a difficult task. For these reasons, we have modeled the PIN diodes or a MEMS component by ribbons of dimension $1 \mathrm{~mm} \times 1.5 \mathrm{~mm}$ in order to prove the concept. The "On" state is illustrated by the presence of the corresponding ribbon, and the "Off" state is presented by the omission of the line. Losses are not taken into account. Six modes of operation have been observed.

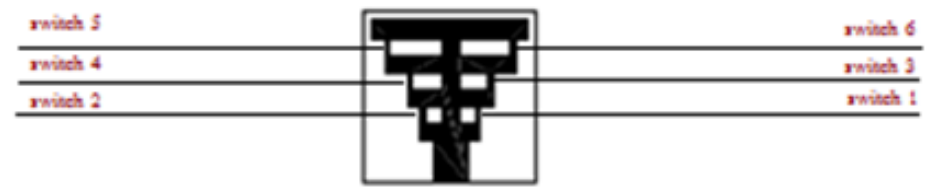

Figure 5. Position of all Switches

Six prototypes, corresponding to the six modes described above, were carried out and experimentally characterized. The antenna images are shown in Figure 10.

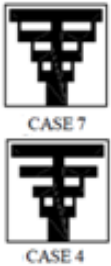

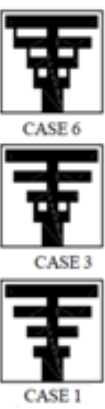

(a)
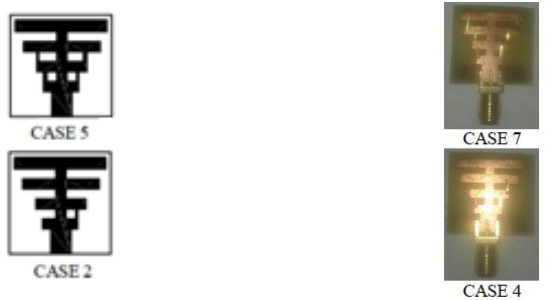

(b)
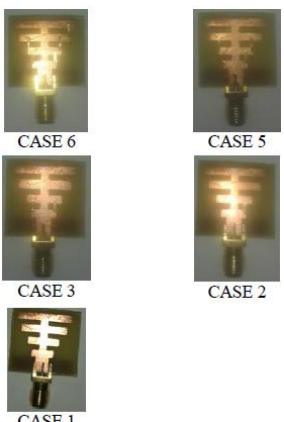

Figure 6. Proposed antenna (a) All cases using electromagnetic simulator CST (b) All fabricated prototype using LPKF machine photo for each case 
Depending on the states of the microstrip line integrated into the position ("On" or "off"), the antenna is capable of redirecting the current flow and switching between six frequencies bands (six different configurations). Figures 7, 8, 9 and 10 show the simulated and measured reflection coefficients of the reconfigurable antenna at the selected operating modes S1, S2, S3, S4, S5, and S6. A good agreement can be observed between the simulation and the measurements. The target frequencies are achieved successfully. It is important to note that several operating modes removed by changing the state of the proposed RF Switch. We have 64 different states, but since we have repetition in results, we present 6 states showing a movement of the peak frequency response in the $\mathrm{S}$-band and the desired frequency reconfiguration.

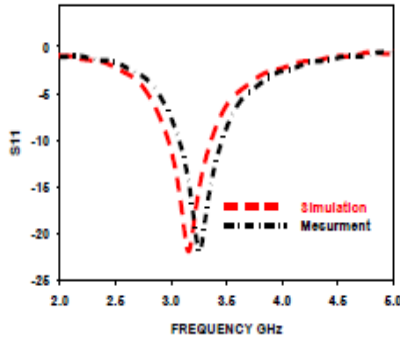

(a)

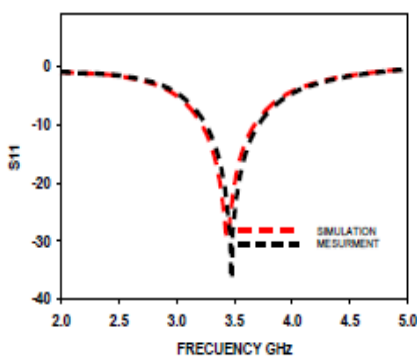

(d)

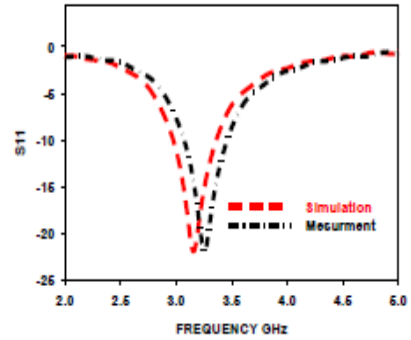

(b)

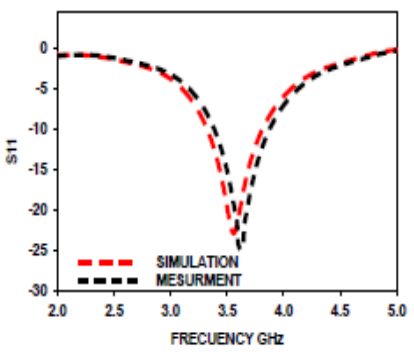

(e)



(i)

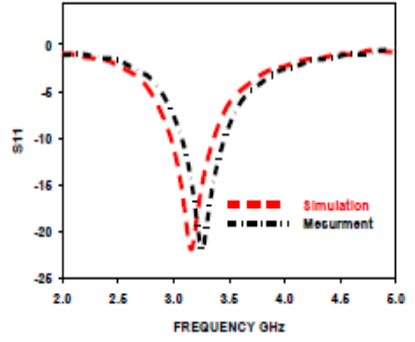

(c)

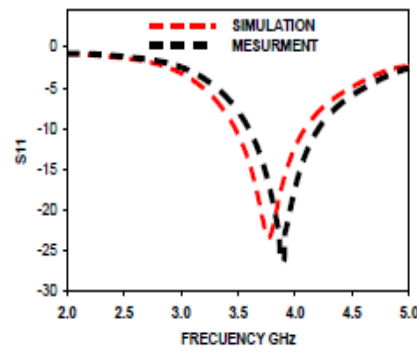

(f)

Figure 7. Mesured and simulated return loss plot of antenna (a) Case 1 without switches-Mode1 (b)Case 2-Mode2 one switch (c) Case 3-Mode3 two switches (d) Case 4-Mode4 three switches (e) Case 5-Mode5 four switches (f) Case 6-Mode6 five switches (i) Case 7-Mode7 six switches

- $\quad$ Mode 1 from Figure 7 (a) the bandwidth of the antenna calculated at $-10 \mathrm{~dB}$ is $383 \mathrm{MHz}(3.07 \mathrm{GHz}$ : $3.453 \mathrm{GHz}$ ). And it is also concluded that the return loss at $3.257 \mathrm{GHz}$ is $-21.68 \mathrm{~dB}$.

- $\quad$ Mode 2 from Figure 7 (b) the bandwidth of the antenna calculated at $-10 \mathrm{~dB}$ is $379 \mathrm{MHz}(3.091 \mathrm{GHz}$ : $3.47 \mathrm{GHz}$ ). And it is also concluded that the return loss at $3.269 \mathrm{GHz}$ is $-35.78 \mathrm{~dB}$.

- $\quad$ Mode 3 from Figure 7 (c) the bandwidth of the antenna calculated at $-10 \mathrm{~dB}$ is $400 \mathrm{MHz}(3.11 \mathrm{GHz}$ : $3.51 \mathrm{GHz}$ ). And it is also concluded that the return loss at $3.29 \mathrm{GHz}$ is $-36.22 \mathrm{~dB}$.

- Mode 4 from Figure 7 (d) the bandwidth of the antenna calculated at $-10 \mathrm{~dB}$ is $440 \mathrm{MHz}(3.27 \mathrm{GHz}$ : $3.71 \mathrm{GHz}$ ). And it is also concluded that the return loss at $3.48 \mathrm{GHz}$ is $-35.93 \mathrm{~dB}$.

- $\quad$ Mode 5 from Figure 7 (e) the bandwidth of the antenna calculated at $-10 \mathrm{~dB}$ is $500 \mathrm{MHz}(3.39 \mathrm{GHz}$ : $3.89 \mathrm{GHz}$ ). And it is also concluded that the return loss at $3.62 \mathrm{GHz}$ is $-25.11 \mathrm{~dB}$.

- Mode 6 From Figure 7 (f) the bandwidth of the antenna calculated at $-10 \mathrm{~dB}$ is $630 \mathrm{MHz}(3.59 \mathrm{GHz}$ : $4.228 \mathrm{GHz}$ ). And it is also concluded that the return loss at $3.91 \mathrm{GHz}$ is $-26.01 \mathrm{~dB}$. 
- $\quad$ Mode 7 from Figure 7 (i) the bandwidth of the antenna calculated at $-10 \mathrm{~dB}$ is $850 \mathrm{MHz}(3.62 \mathrm{GHz}-$ $4.47 \mathrm{GHz}$ ). And it is also concluded that the return loss at $4 \mathrm{GHz}$ is $-20 \mathrm{~dB}$

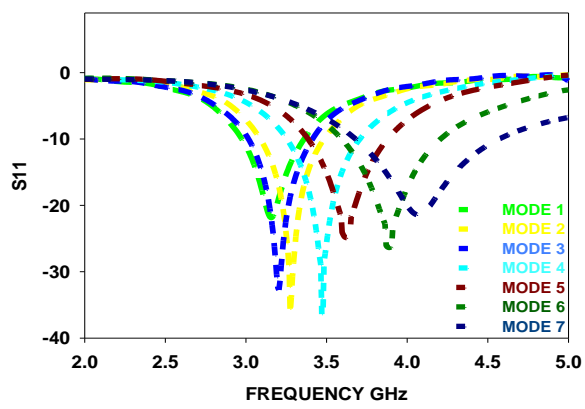

Figure 8. Measured return loss plot of all cases

The figure 8 clearly shows a displacement of the peak of the frequency response of the proposed antenna by passing from one mode to another mode. The bandwidth calculation confirms the frequency reconfiguration for our prototype

Figures 9 plot the simulated radiation patterns E-plan and $\mathrm{H}$-plan at $3.257 \mathrm{GHz}, 3.269 \mathrm{GHz}$, $3.29 \mathrm{GHz}, 3.48 \mathrm{GHz}, 3.62 \mathrm{GHz}, 3.91 \mathrm{GHz}$ and $4 \mathrm{GHz}$. Similarly to the conventional monopole antenna, the radiation patterns of the proposed antenna are nearly unidirectional over the operating bandwidth.
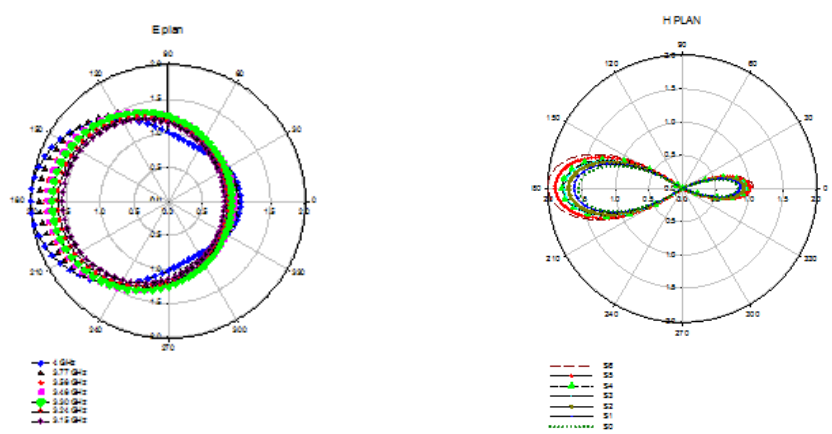

Figure 9. Polar plot of the E and $\mathrm{H}$ plan at $3.257 \mathrm{GHz}, 3.269 \mathrm{GHz}, 3.29 \mathrm{GHz}, 3.48 \mathrm{GHz}, 3.62 \mathrm{GHz}$, $3.91 \mathrm{GHz}$ and $4 \mathrm{GHz}$

To understand the influence of the RF switches addition on the antenna behaviour, figure 10 shows the distribution of the surface current for the six states. The insertion of the Switch attracts differently the surface current generating different frequency responses which mean a tuning of the resonant frequencies.

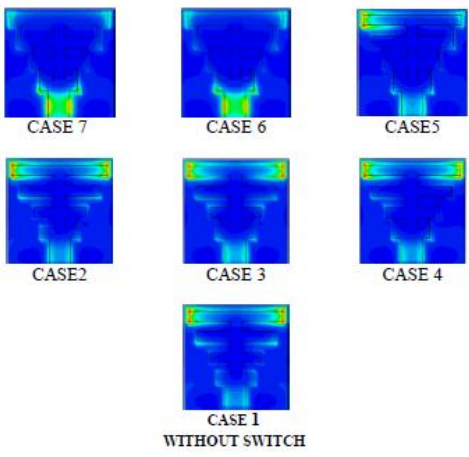

Figure 10. Distribution of current surface for all states 
The 3D radiation patterns were simulated at different frequencies and for each selected mode. Figure 11 shows some 3D radiation patterns at $3.156 \mathrm{GHz}, 3.24 \mathrm{GHz}, 3.3 \mathrm{GHz}, 3.46 \mathrm{GHz}, 3.56 \mathrm{GHz}, 3.77 \mathrm{GHz}$ and $4 \mathrm{GHz}$.



(a)

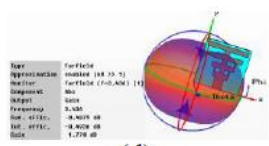

(d)

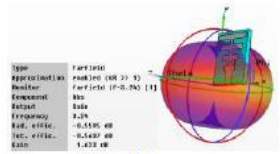

(b)

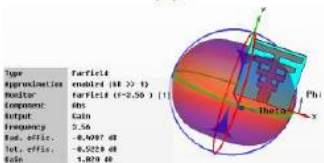

(e)

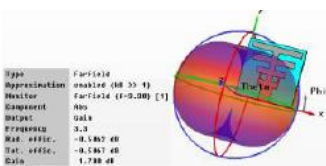

(c)

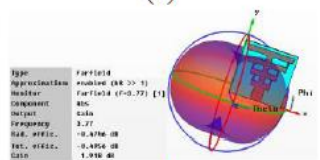

(f)

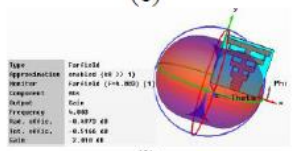

(j)

Figure 11. 3D radiation pattern at; (a) $3.156 \mathrm{GHz}$, (b) $3.24 \mathrm{GHz}$, (c) $3.3 \mathrm{GHz}$, (d) $3.463 \mathrm{GHz}$, (e) $3.56 \mathrm{GHz}$, (f) $3.77 \mathrm{GHz}$, (j) $4 \mathrm{GHz}$.

Talking about the antenna gain, the figure 12 shows the antenna gain's in the frequency band $3 \mathrm{GHz}-4 \mathrm{GHz}$, as it is shown. If we consider the resonance frequency for each studied case, we can say that the gain is so acceptable for the $\mathrm{S}$ band if we take into consideration the antenna miniature size which does not exceed $20 \mathrm{~mm} * 20 \mathrm{~mm}$. The gain for the mode $3.156 \mathrm{GHz}, 3.24 \mathrm{GHz}, 3.3 \mathrm{GHz}, 3.463 \mathrm{GHz}, 3.56 \mathrm{GHz}, 3.77 \mathrm{GHz}$ and $4 \mathrm{GHz}$ is successively $0.5 \mathrm{~dB}, 1.42 \mathrm{~dB}, 1.7 \mathrm{~dB}, 1.72 \mathrm{~dB}, 1.82 \mathrm{~dB}, 1.9 \mathrm{~dB}, 2.02 \mathrm{~dB}$

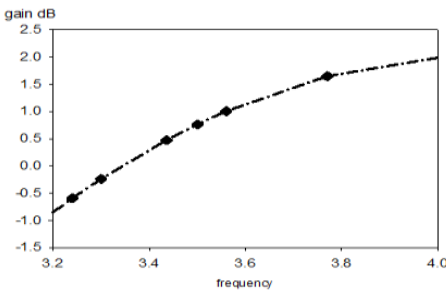

Figure 12. Plot of gain $(\mathrm{dB})$ of antenna from $3.2 \mathrm{GHz}$ to $4 \mathrm{GHz}$

\section{CONCLUSION}

We have succeeded in designing a reconfigurable frequency antenna capable of operating on six different frequency bands with very acceptable radiation performance. Despite the technological constraints associated with the uses of six Switches to ensure frequency tuning, we were able to validate our theoretical study using ribbon segments instead of PIN diodes in order to prove the concept. With regard to the size of the prototype involved $20 \mathrm{~mm} * 20 \mathrm{~mm} * 1.6$, it can be incorporated into only a portable element in view of its small size. The radiation performance described in the fourth paragraph shows an efficient antenna for all six manufactured prototypes for the S-band.

\section{REFERENCES}

[1] J. H. Winters, "Smart antennas for wireless systems," Personal Communications, IEEE , vol. 5, no. 1, pp. 23-27, Feb. 1998

[2] Nooshin Feiz, et al, "Optimized Microstrip Antennas with Metamaterial Superstrates using Particle Swarm Optimization," Bulletin of Electrical Engineering and Informatics, vol. 2, pp. 123 131, June 2013

[3] D. Schaubet. "Frequency-Agile Polarization Diverse Microstrip Antennas and Frequency Scanned Arrays [P]", US Patent \#4, 367, 474, Jan. 4, 1983. 
[4] S. Nikolaou, N. D. Kingsley, G. E. Ponchak, J.Papapolymerou, and M. M. Tentzeris, "UWB Elliptical Monopoles with a Reconfi gurable Band Notch Using MEMS Switches Actuated Without Bias Lines, " IEEE Transactions on Antennas and Propagation, August 2009, AP-57, 8, pp. 2242-2251.

[5] A. Sheta and S. F. Mahmoud, "A widely tunable compact patch antenna,"IEEE Antennas Wireless Propag. Lett., Vol. 7, pp. 40-42, March. 2008.

[6] A. Mak, C. Rowell, R. Murch, and C. Mak, "Reconfigurable multiband antenna designs for wireless communication devices, " IEEE Trans. Antennas Propag., Vol. 55, No. 7, pp. 1919-1928, July. 2007.

[7] Omar Lehmer. Farid Ben Abdelouahab, MoEssaaidi, "A Reconfigurable Antenna for Digital Video Broadcasting for Handheld Receivers," International journal of microwave and optical technology, Vol. 11, No.4, pp.219-226, July. 2016

[8] N. Behd ad and K. Sarabandi, "A Varactor-Tuned Dual-Band Slot Antenna," IEEE Transactions on Antennas and Propagation, AP-54, 2, February 2006, pp. 401- 408.

[9] C. J. Panagamuwa, A. Chauraya, and J. C. Vardaxoglou, BFrequency and beam reconfigurable antenna using photoconductive switches, "IEEE Trans. Antennas Propag., vol. 54, no. 2, pp. 449-454, Feb. 2006.

[10] Y. Tawk, A. R. Albrecht, S. Hemmady, G. Balakrishnan, and C. G. Christodoulou, "BOptically pumped frequency reconfigurable antenna design, " IEEE Antennas Wireless Propag. Lett., vol. 9, pp. 280-283, 2010.

[11] P. Tummas P. Krachodnok ; R. Wongsan, "A frequency reconfigurable antenna design for UWB applications, " IEEE Transactions on Antennas and Propagation2014, 10.1109/ECTICon

[12] K. Tagantsev, V. O. Sherman, K. F. Astafiev, J. Venkatesh, and N. Setter, "Ferroelectric Materials for Micro wav e Tunable Applications," Journal of Electroceramics, 11, 2003, pp. 5-66.

[13] S. Kwon, W. Hackenberger, E. Alberta, E. Furman, and M. Lanagan, "Nonlinear Dielectric Ceramics and their Applications to Capacitors and Tunable Dielectrics, " IEEE Electrical Insulation Magazine, 2011

[14] Erna Risfaula Kusumawati, et al.," Optically Switched Frequency for Reconfigurable Dipole Antenna Using Photodiode Switches" TELKOMNIKA, Vol.14, No.4, December 2016, PP. 1351 1355

[15] M. Mirsaneh, E. Furman, J. V. Ryan, M. T. Lanagan, and C. G. Pantano, "Frequency Dependent Electrical Measurements of Amorphous GeSbSeChalcogenide Thin Films," Applied Physics Letters, 2010, vol 96, p. 112907.

[16] Computer Simulation Technology, www.cst.com

[17] K. Grenier, "Design, realization and characterization of micro-machined structures on silicon: applications to micro-systems", chap.1, November 2000).

[18] C. Goldsmith, T.H. Lin, B. Powers, W. R. Wu, and B.Norvell, "Micromechanical membrane switches for microwave applications," IEEE MTT-S Int. Microwave Symp, 1995, p.91-94.

[19] C. Goldsmith, J. Randall, S. Eshelman, T-H. Lin, D. Denniston, S. Chen, B. Norvell, 'Characteristics of micromachined switches at microwave frequencies', IEEE MTT-S Digest,pp. 1141-1144, 1996.

[20] J. Randall, C. Goldsmith, D. Denniston, T-H. Lin, 'Fabrication of micromechanical switches for routing radio frequency signals', J. Vac. Sci. Technol. B 14(6), pp. 3692-3696, November/December 1996.

[21] Randy L. Haupt and Michael Lanagan, ”Reconfi gurable Antennas, " IEEE Antennas and Propagation Magazine, Vol. 55, No. 1, February 2013

[22] P. D. Grant, M. W. Denhoff, and R. R. Mansour, "A Comparison between RF MEMS and Semiconduc tor Switches," ICMENS, August 25-27, 2004, pp. 515- 521.

[23] R.B. Waterhouse \& N.V. Shuley "Scan performance of infinite arrays of microstrip patches elements loaded with varactor diodes" IEEE Trans. On Antennas and propagation, Vol. 41, no9, pp. 1273-1279, septembre 1993

[24] S.R. Chandler, I.C. Hunter \& J.G. Gardiner "Active varactors tunable bandpass filter" IEEE Microwave and Guided Wave Letters, Vol.3, no3, pp.70-71, Mars 1993

[25] "The PIN Diode Circuit Designers' Handbook," Microsemi Corp., Watertown, MA, 1998.

[26] L. N. Pringle, et al., "A Reconfigurable Aperture Antenna Based on Switched Links between Electrically Small Metallic Patches," IEEE Transactions on Antennas and Propagation, AP-52, 6, June 2004, pp. 1434- 1445.

[27] C-C. Chang, Y. Qian \& T. Itoh, "A reconfigurable leaky mode/ patch antenna controlled by PIN diode switches" IEEE AP-S International Symposium Digest, Orlando, 1999, FL, Vol.4, PP.2694-2697, 1999 